\title{
STRENGTH, THERMAL DEFECTS, AND SOLID SOLUTION HARDENING IN NICKEL-CONTAINING B2 IRON ALUMINIDES
}

\author{
J.H. SCHNEIBEL*, P.R. MUNROE**, AND L.M. PIKE***
}

*Metals and Ceramics Division, Oak Ridge National Laboratory, Oak Ridge, TN 37831-6115

**School of Materials Science and Engineering, University of New South Wales. Sydney, NSW 2052 Australia ***Dept. of MS\&E. University of Wisconsin-Madison, Madison, WI 53706-1595

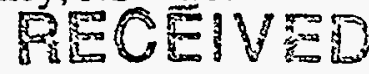

JAN 281997

\section{ABSTRACT}

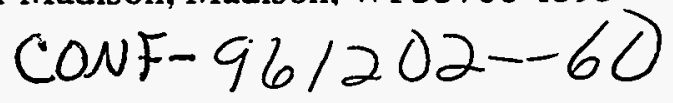

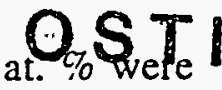

Nickel-containing ternary iron aluminides with an aluminum concentration of 45 at. investigated with respect to room temperature strength, equilibrium vacancy concentration. and the
kinetics of vacancy removal. As compared to binary iron aluminides with the same Al concentration. nickel additions reduce the thermal equilibrium vacancy concentration at $1273 \mathrm{~K}$. whereas they increase this concentration at $973 \mathrm{~K}$. Furthermore, at low temperatures such as $673 \mathrm{~K}$. nickel additions increase dramatically the time needed to reach vacancy equilibrium. During prolonged annealing at $673 \mathrm{~K}$. the density of $<001>$ dislocations in Fe-45Al-3Ni (at. \%) increased by an order of magnitude. This suggests that dislocations act as sinks for vacancies. At the same time. the number density of small $(20-50 \mathrm{~nm})$ voids decreased. indicating that they were not stable in the absence of substantial vacancy supersaturations. Our findings show also that the solid solution strengthening of iron aluminides due to $\mathrm{Ni}$ is much weaker than previously thought.

\section{INTRODUCTION}

Iron aluminides with the $\mathrm{B} 2$ structure (Fe- $\mathrm{x}$ at. \% $\mathrm{Al}$, where 23 at. $\%<\mathrm{x}<55$ at. \%) are known to contain high concentrations of thermal vacancies at elevated temperatures. These thermal vacancies may be inferred from changes in length and lattice parameter [1-3], electrical resistivity [4-6] and hardness $[7,8]$; they may also be measured by positron annihilation $[9,10]$ and they are predicted from first principles calculations [11]. Following the work of Nagpal and Baker [7], it has become common practice to anneal iron aluminide specimens for 5 days at $673 \mathrm{~K}$ prior to mechanical testing. The goal of this long-term, low-temperature anneal is to reach the relatively low equilibrium vacancy concentration corresponding to $673 \mathrm{~K}$ in order to obtain mechanical data with no or negligible interference from strengthening due to vacancies.

Ternary iron aluminides subjected to a 5 day $/ 673 \mathrm{~K}$ heat treatment are often significantly stronger at room temperature than the corresponding binary alloys [12-18]. This has been attributed to solid solution strengthening. Experiments carried out with ternary B2 iron aluminides with the composition Fe-45Al-5X (at. \%), where X is a 3d transition element such as Ti, V, Cr, Mn. Co, Ni, or Cu showed that the strengthening could be reasonably well correlated with the magnitude of the atomic size misfit of the ternary alloying addition $[17,18]$. One notable exception, however, was found for nickel additions: $\mathrm{Fe}-45 \mathrm{Al}-5 \mathrm{Ni}$ was much stronger than expected from the atomic size misfit correlation alone. It was therefore felt necessary to reexamine the solid solution hardening due to nickel. In particular, it had to be determined whether a 5 day $/ 673 \mathrm{~K}$ anneal was sufficient to reduce the vacancy concentration to levels which would not unduly influence the mechanical properties. In order to minimize grain size effects, cast and annealed materials were used (as opposed to extruded materials in previous work $[17,18]$, which had relatively small grain sizes ranging from 20 to $80 \mu \mathrm{m}$ ). Also, vacancy concentrations were determined via $\mathrm{x}$-ray lattice spacing and bulk density (pycnometric) measurements. The analysis of these data shows that the direct (i.e., without vacancies) strengthening of iron aluminides by nickel alloying additions is much weaker than previously thought.

\section{EXPERIMENTAL PROCEDURE}

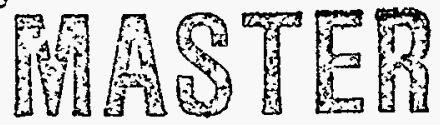

Iron aluminides containing 45 at. $\% \mathrm{Al}$ and different concentrations of $\mathrm{Ni}$ (up to 5.5 at. \%) were prepared by arc-melting elemental raw materials into buttons in a partial pressure of argon. The melting was repeated several times in order to ensure homogeneity. Following vacuum homogenization anneals at temperatures ranging from 1273 to $1423 \mathrm{~K}$, some buttons were crushed into -200 mesh powder, annealed at 973 or $1273 \mathrm{~K}$, and quenched for subsequent $\mathrm{x}$-ray analysis and

The submitted manuscript has been authored by a contractor of the U.S. Government under contract No. DE-AC0596OR22464. Accordingly, the U.S. Govemment retans a nonexclusive, royalty-free license to publish or reproduce the 


\section{DISCLAIMER}

Portions of this document may be illegible in electronic image products. Images are produced from the best available original document. 


\section{DISCLAIMER}

This report was prepared as an account of work sponsored by an agency of the United States Government. Neither the United States Government nor any agency thereof, nor any of their employees, make any warranty, express or implied, or assumes any legal liability or responsibility for the accuracy, completeness, or usefulness of any information, apparatus, product, or process disclosed, or represents that its use would not infringe privately owned rights. Reference herein to any specific commercial product, process, or service by trade name, trademark, manufacturer, or otherwise does not necessarily constitute or imply its endorsement, recommendation, or favoring by the United States Government or any agency thereof. The views and opinions of authors expressed herein do not necessarily state or reflect those of the United States Government or any agency thereof. 
bylk density measurements. The density measurements were carried out on coarse powders $(-40 /+80$ mesh) in order to minimize errors due to internal porosity in the castings. Atomic vacancy concentrations $c^{a}$ were determined as $c^{a}=\left(\rho_{x}-\rho_{b}\right) / \rho_{b}$, where $\rho_{x}$ is the density determined from the lattice parameter, the crystal structure, and the known composition, and $\rho_{b}$ the bulk (pycnometric) density determined by weighing the powders in air and in a liquid of known density, respectively. Compression specimens with typical dimensions of $5 \times 5 \times 10 \mathrm{~mm}$ were machined from cast and homogenized bars ( $1 \mathrm{~h}$ at $1273 \mathrm{~K}$ followed by cooling at a rate of $0.1 \mathrm{~K} / \mathrm{s}$ ). Following machining, the compression specimens were annealed for up to 40 days at $673 \mathrm{~K}$ in air and tested at room temperature to determine their $0.2 \%$ offset yield stress. Since the grain sizes ranged from 250 to $800 \mu \mathrm{m}$. HallPetch strengthening was not likely to be a factor. In order to study the kinetics of the vacancy removal as precisely as possible, the density of relatively large specimens (approximately $10 \times 20 \times 20 \mathrm{~mm}$ ) was measured as a function of annealing time at $673 \mathrm{~K}$. From the changes in the density, the changes in the vacancy concentrations were determined. Since these specimens contained internal casting porosity, the measured densities were lower than those obtained from measurements using crushed powders. However, since the specimens had a larger mass, and a smaller surface area than the crushed powders, the accuracy of the density measurements. as verified by a Si standard. was approximately 1 part in 10,000 , vs. 1 part in 1000 for the powder technique. The technique using large specimens was therefore well suited for comparing the densities of the same block of material after different heat treatments. Transmission electron microscope (TEM) specimens were prepared from $\mathrm{Fe}-45 \mathrm{Al}-3 \mathrm{Ni}$ after different annealing treatments and examined in a TEM to determine their dislocation and void microstructure.

\section{RESULTS AND DISCUSSION}

After a vacuum anneal of $1 \mathrm{~h}$ at $1273 \mathrm{~K}$ followed by a cool-down at a rate of $0.1 \mathrm{~K} / \mathrm{s}$, cast iron aluminides containing between 0 and 3 at. $\% \mathrm{Ni}$ were annealed for up to 40 days at $673 \mathrm{~K}$. After each anneal, two specimens for each of the four different compositions studied were tested in compression to determine the yield strength (see Fig. 1). The yield strength data shows some scatter whicn is likely to be due to casting defects such as pores and cracks, as well as the large grain size. Nevertheless. several trends are readily discemed from Fig. 1 and also from Fig. 2, which shows the yield stress data as a function of the Ni content. First, immediately after the $1273 \mathrm{~K}$ anneal. the material containing 0.1 at. \% $\mathrm{Ni}$ is stronger than that containing 3 at. \% Ni. After sufficiently long annealing at $673 \mathrm{~K}$, the yield stresses increase with increasing $\mathrm{Ni}$ content. Second, as the nickel content increases, the rate with which the yield strength decreases during annealing at $673 \mathrm{~K}$ becomes lower and lower. As the annealing at $673 \mathrm{~K}$ proceeds, the yield strengths of all the alloys decrease. Previous work $(1-11)$ suggests that this decrease is due to the removal of vacancies. In the alloys containing 2 or 3 at. $\% \mathrm{Ni}$, more than 40 days at $673 \mathrm{~K}$ would be required to reach the lowest possible yield stresses. Therefore, the commonly used heat treatment of 5 days at $673 \mathrm{~K}$ is not long enough to reach the equilibrium vacancy concentration corresponding to $673 \mathrm{~K}$ in those alloys.

The slow rate of the vacancy removal at $673 \mathrm{~K}$ is supported by the pycnometric density measurements shown in Fig. 3. Since the specimens with which these measurements were made contained internal porosity, only density differences are plotted. The density difference at the beginning of the $673 \mathrm{~K}$ anneals was arbitrarily set to 0 . Exponential functions proportional to $\left[1-\exp \left(-t / \tau_{r}\right)\right]$ were fitted through the data points in order to determine a characteristic time $\tau_{r}$ for vacancy removal at $673 \mathrm{~K}$. It is seen that even small additions of $\mathrm{Ni}$ increase $\tau_{\mathrm{r}}$ significantly. An addition of 3 at. \% Ni increases $\tau_{\mathrm{r}}$ by almost a factor of 20 . The effect of $\mathrm{Ni}$ is opposite to that of small additions of $\mathrm{B}(0.02$ at. \%). Those enhance the kinetics of vacancy removal in iron aluminides containing 40 at. \% by approximately a factor of 6 [3].

The results suggest that the hardening due to $\mathrm{Ni}$ is not nearly as pronounced as thought in earlier studies [12-18]. In those studies, the vacancy removal anneals at $673 \mathrm{~K}$ were terminated after 5 or 7 days, which was most likely not long enough to reach the vacancy equilibrium corresponding to this temperature. For example, a Fe-45Al-5Ni alloy containing small amounts of $\mathrm{B}$ and $\mathrm{Zr}$ exhibited a yield stress close to $550 \mathrm{MPa}$, which is much higher than would be expected from Fig. 2. Therefore, indirect hardening due to frozen-in vacancies was probably a factor in those studies. 


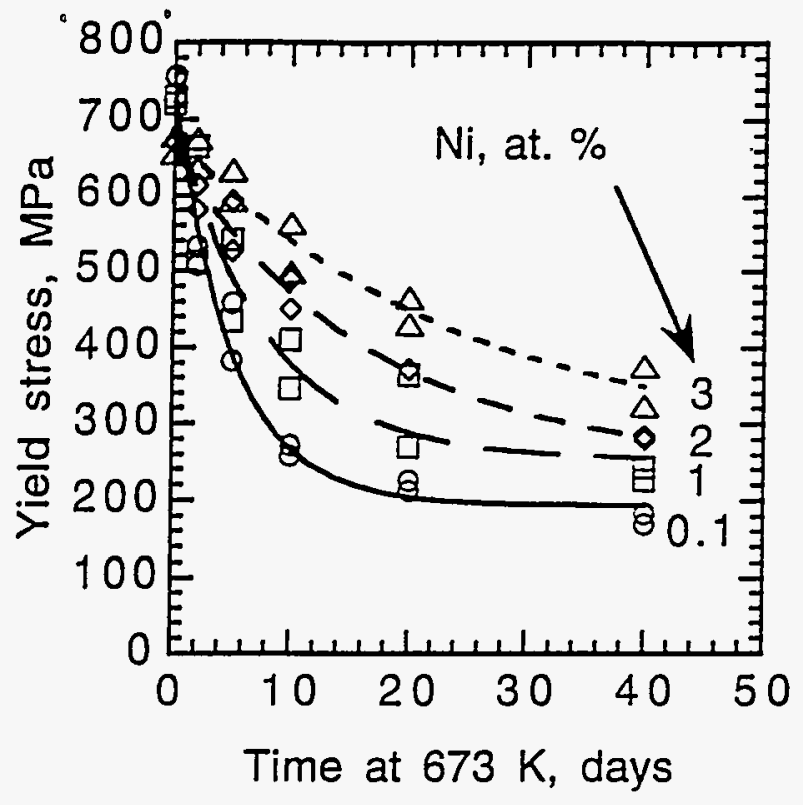

Fig. 1. Yield stresses of Ni-containing iron aluminides after annealing for different periods of time at $673 \mathrm{~K}$. Prior to the $673 \mathrm{~K}$ anneal, the cast ingots were annealed for $1 \mathrm{~h}$ at $1273 \mathrm{~K}$ and cooled at a rate of $0.1 \mathrm{~K} / \mathrm{s}$.

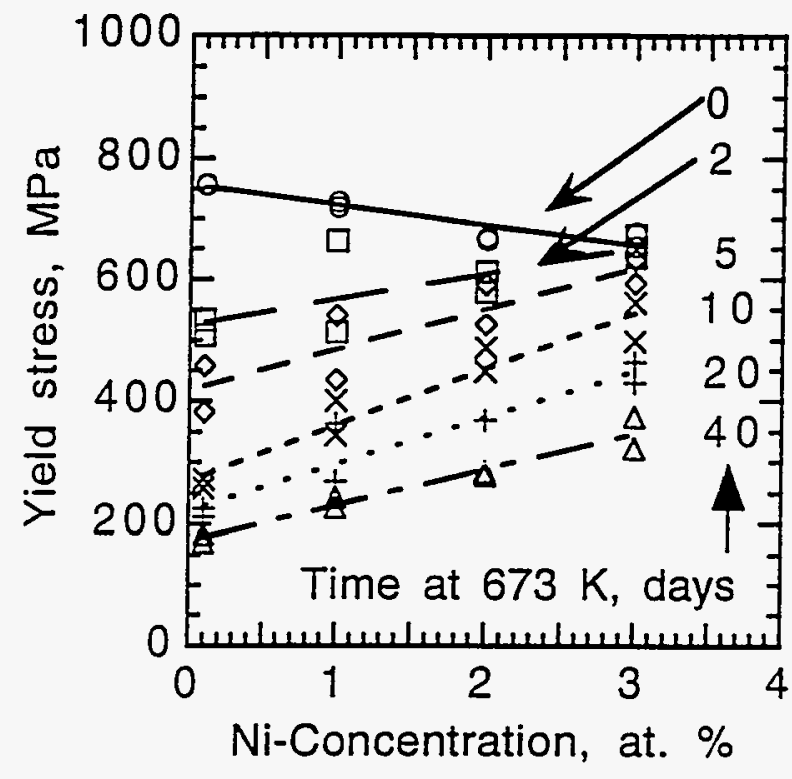

Fig. 2. Yield stresses in Fig. 1 plotted as a function of the $\mathrm{Ni}$ concentration, with the annealing time at $673 \mathrm{~K}$ as parameter.

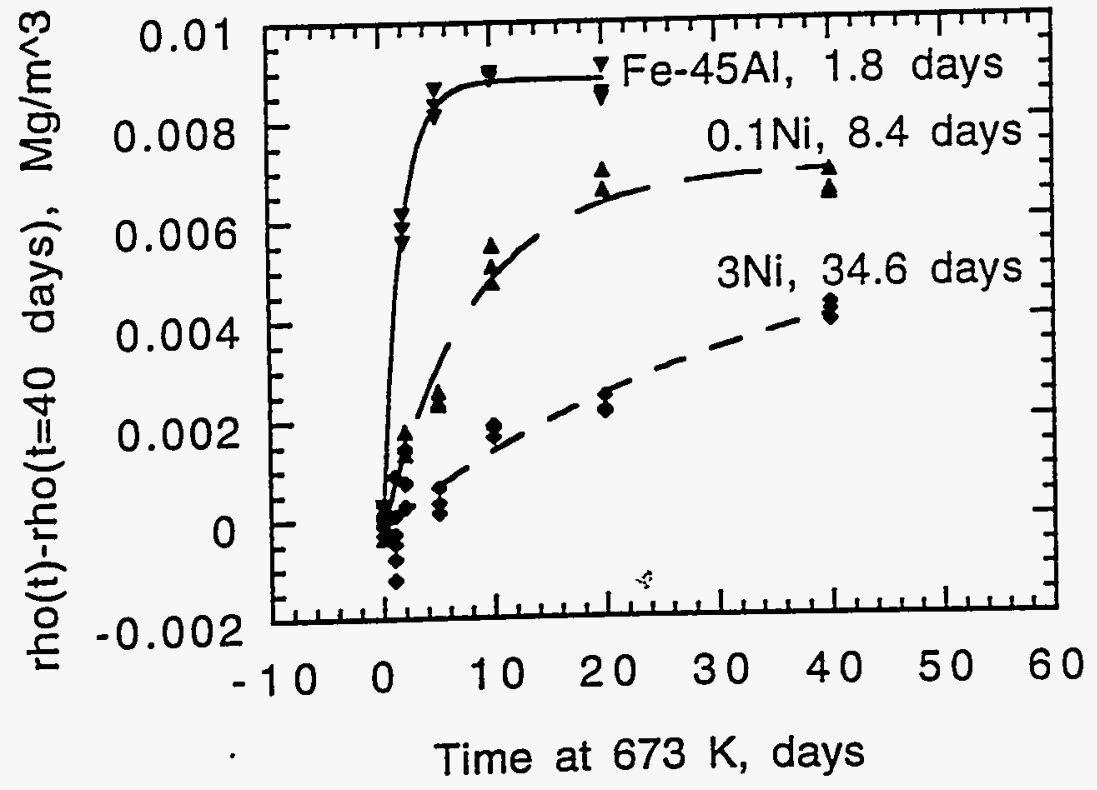

Fig. 3. Density changes during annealing at $673 \mathrm{~K}$. The characteristic times for vacancy removal, $\tau_{\Gamma}$, are indicated in days.

The microstructural changes occurring during heat treatment of binary and ternary iron aluminides have been studied in considerable detail by Munroe and collaborators [12-16]. TEM work carried out for Fe-45 Al-3Ni directly after the $1 \mathrm{~h} / 1273 \mathrm{~K}$ anneal, and with an additional 10 day $/ 673 \mathrm{~K}$ anneal is in general agreement with this previous work. Although the drop in the yield strength and the increase in the density after 10 days at $673 \mathrm{~K}$ are small, the microstructure changes significantly. Figures 4 (a) and (b) show TEM micrographs of the microstructure immediately after the high-temperature $1273 \mathrm{~K}$ anneal. Figure 4 (a) illustrates low densities of $<001>$ edge dislocations (approximately $10^{12} / \mathrm{m}^{2}$ ). In iron aluminides such dislocations nucleate during vacancy removal and are thought to be sinks for vacancies. Figure 4 (b) shows small cuboidal voids with diameters between 20 and $50 \mathrm{~nm}$. These voids were usually observed in areas were the density of dislocations was particularly low. This suggests that during the cool-down from $1273 \mathrm{~K}$ void formation operated as an alternative mechanism 
for vacancy removal. After an additional anneal for 10 days at $673 \mathrm{~K}$, the microstructure looks very different (Fig. 5). The dislocations are now much more homogeneously distributed with a much higher density (approximately $10^{13} / \mathrm{m}^{2}$ ). The number of voids has become significantly smaller. This suggests that the voids shrink once the vacancy supersaturation has become sufficiently low, and that they act as the sources for vacancies, which then nucleate dislocations and/or annihilate at dislocations.
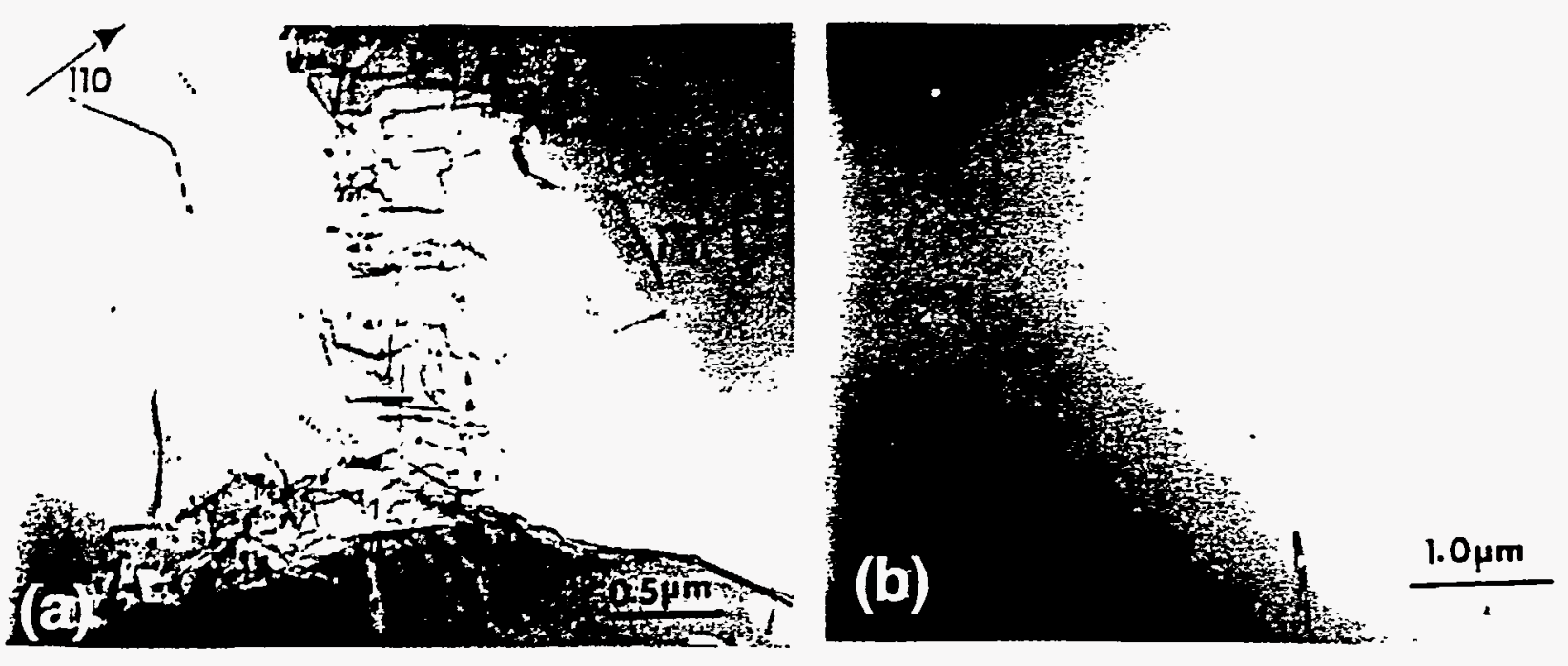

Fig. 4. Transmission electron micrographs of Fe-45AI-3Ni annealed for $\mathrm{lh}$ at $1273 \mathrm{~K}$ and cooled at $0.1 \mathrm{~K} / \mathrm{s}$ show (a) $<100>$ dislocation networks and (b) small voids.

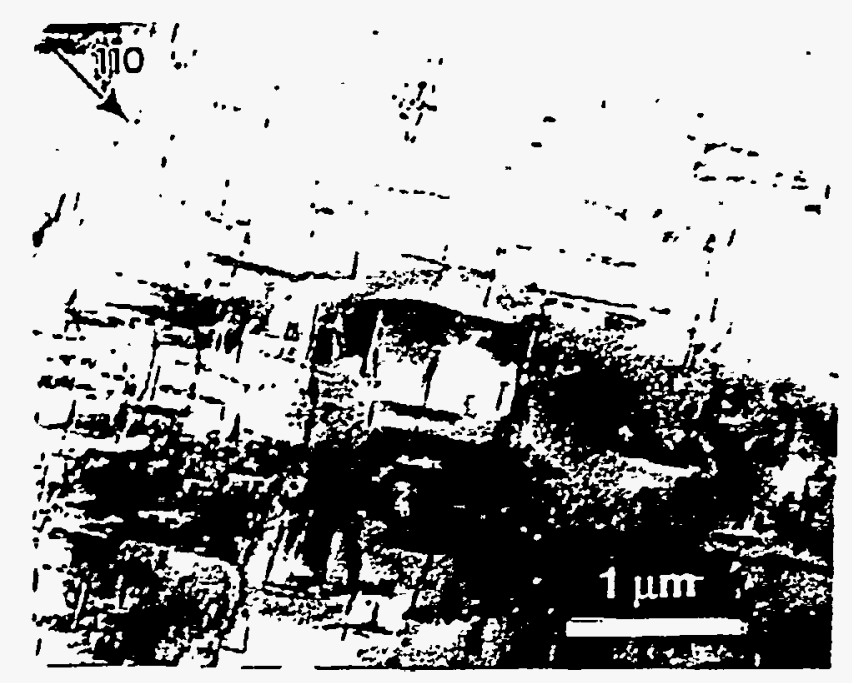

Fig. 5. Transmission electron micrograph of $\mathrm{Fe}-$ $45 \mathrm{Al}-3 \mathrm{Ni}$ annealed for $1 \mathrm{~h}$ at $1273 \mathrm{~K}$. cooled at $0.1 \mathrm{~K} / \mathrm{s}$. and annealed for 10 days at $673 \mathrm{~K}$ shows homogeneous networks of $<001\rangle$ dislocations. Only few voids were observed in this heat treatment condition.

In order to better understand the recovery effects in Figs. 1 and 2, we need to know the vacancy concentrations as a function of annealing time at $673 \mathrm{~K}$. Table I lists the vacancy concentrations as well as the densities measured for two nickel-containing iron aluminides after quenching from 973 and $1273 \mathrm{~K}$. The data show (1) that $\mathrm{Ni}$ additions reduce the equilibrium vacancy concentration at elevated temperatures such as $1273 \mathrm{~K}$ and (2) that they increase this concentration at lower temperatures. The reduction of the high-temperature vacancy concentration by $\mathrm{Ni}$ additions may be one reason why the $\mathrm{Ni}$-containing alloys are weaker than Fe-45Al immediately after the $1273 \mathrm{~K}$ anneal (Fig. 2). It appears that the reduction in the vacancy concentration by $\mathrm{Ni}$ additions outweighed in this case the slowing down of the vacancy removal. 
Table I. Measured bulk densities, and measured and extrapolated equilibrium vacancy concentrations

\begin{tabular}{|c|cc|cc|cc|}
\hline & \multicolumn{2}{|c|}{ Fe-45Al } & \multicolumn{2}{c|}{ Fe-45Al-2.2Ni } & \multicolumn{2}{c|}{ Fe-45Al-5.5Ni } \\
\hline Temperature. K & $\mathrm{c}^{\text {a }}$ at. \% & 0. $\mathrm{Mg} / \mathrm{m}^{3}$ & $\mathrm{c}^{\mathrm{a}}$. at. \% & 0. $\mathrm{Mg} / \mathrm{m}^{3}$ & $\mathrm{c}^{\mathrm{a}}$. at. \% & $\rho . \mathrm{Mg} / \mathrm{m}^{3}$ \\
\hline 1273 & 0.95 & 5.7810 & 0.80 & 5.7957 & 0.82 & 5.8240 \\
973 & 0.14 & 5.8089 & 0.22 & 5.8240 & 0.32 & 5.8455 \\
673 (extrapolated) & 0.0037 & & 0.019 & & 0.054 & \\
\hline
\end{tabular}

Assuming an $\exp (-\Delta \mathrm{H} / \mathrm{kT})$ Arrhenius-type relationship, the vacancy concentrations were extrapolated to $673 \mathrm{~K}$ in order to obtain an estimate of the vacancy equilibrium concentration at this temperature. The data suggests the possibility that $\mathrm{Ni}$ additions increase the equilibrium concentration at $673 \mathrm{~K}$. This means that the strengthening observed after 40 days $/ 673 \mathrm{~K}$ for increasing $\mathrm{Ni}$ concentrations in Fig. 2 could be due to vacancies in addition to solid solution effects. However, since the accuracy of the vacancy concentration determinations from lattice parameter and bulk density. measurements was only on the order on $0.1 \%$, no firm conclusion can be drawn.

Table I allows an assessment of the vacancy volume in terms of the atomic volume. The difference in the volume fraction of vacancies between 1273 and $973 \mathrm{~K}$ is given by $\Delta c^{v}=[\rho(973 \mathrm{~K})$ $\rho(1273 \mathrm{~K})] / \rho(1273 \mathrm{~K})$. From Table I one can calculate the corresponding difference in the atomic vacancy concentration, $\Delta c^{a}$. The ratio of the vacancy volume and the atomic volume is then given by $\Delta c^{v} / \Delta c^{a}$. Values ranging from 0.6 to 0.8 were found indicating that the vacancy volume is smaller than the atomic volume.

For the Fe-45Al-0.1Ni alloy, the yield stress and the density are known as a function of the duration of the vacancy removal anneal at $673 \mathrm{~K}$, and, in contrast to $\mathrm{Fe}-45 \mathrm{Al}-3 \mathrm{Ni}$. equilibrium is definitely reached after 40 days at $673 \mathrm{~K}$. The extrapolation in Table I suggests that the vacancy equilibrium concentration at $673 \mathrm{~K}$ is very small, namely, $\mathrm{c}^{\mathrm{a}}(673 \mathrm{~K})=0.0037 \%$. We assume that this concentration is not changed significantly by 0.1 at. $\% \mathrm{Ni}$. The atomic vacancy concentration as a function of the time $t$ at $673 \mathrm{~K}$ is then estimated to be $c^{\mathrm{a}}(t)=c^{\mathrm{a}}(\infty)+(1 / 0.6) \times c^{\mathrm{v}}(\mathrm{t})=\mathrm{c}^{\mathrm{a}}(673$ $\mathrm{K})+(1 / 0.6) \times[\rho(\infty)-\rho(\mathrm{t})] / \rho(\mathrm{t})$, where $\rho(\infty)$ is the equilibrium density (reached after 40 days $673 \mathrm{~K}$ ), $\rho(\mathrm{t})$ the density after time $\mathrm{t}$ at $673 \mathrm{~K}$, and the factor $(1 / 0.6)$ is the ratio between the atomic and vacancy volumes, respectively. For reference purposes, the densities. from which the vacancy volume fractions were determined are listed in Table II together with the corresponding yield stresses.

Table II. Densities (each value is an average of $\geq 3$ measurements) and yield stresses of Fe-45Al-0.1Ni as a function of annealing time at $673 \mathrm{~K}$

\begin{tabular}{ccccccc}
\hline Time at 673 K. days & 0 & 2 & 5 & 10 & 20 & 40 \\
\hline$\rho, \mathrm{Mg} / \mathrm{m}^{3}$ & 5.78626 & 5.78785 & 5.78875 & 5.79144 & 5.79305 & 5.79298 \\
Yield Stress, $\mathrm{MPa}$ & 756.00 & 533.00 & 458.00 & 258.00 & 226.00 & 184.00 \\
& 758.00 & $\therefore 508.00$ & 383.00 & 272.00 & 212.00 & 170.00 \\
\hline
\end{tabular}

Figure 6 shows the yield stress as a function of the vacancy concentration for Fe-45Al-0.1Ni. Interestingly, the yield stress does not follow a $\mathrm{c}^{1 / 2} \mathrm{law}$, as might be expected from Chang et al.'s [8] hardness measurements for binary iron aluminides, but rather a relationship close to $c^{2}$. This result is qualitatively similar to Yang and Baker's [2] results for $\mathrm{Fe}-40$ at. \% Al single and polycrystals. Yang and Baker observe a steep rise in the yield stress up to vacancy concentrations on the order of 0.5 at. $\%$. However, in order to increase the yield strength to values on the order of $600 \mathrm{MPa}, 0.5 \%$ of vacancies were required in that work, as compared to $0.2 \%$ in ours. This difference may be related to the different chemical compositions of the two iron aluminides and needs to be investigated further.

\section{CONCLUSIONS}

We have demonstrated that the kinetics of vacancy removal in ternary iron aluminides is slowed down dramatically by $\mathrm{Ni}$. Therefore, the magnitude of the direct solid solution strengthening by $\mathrm{Ni}$ (i.e., when strengthening due to vacancies can be neglected) is much smaller than previously thought. 
In particular, the vacancy reduction anneals in previous work on $\mathrm{Ni}$-containing $\mathrm{FeAl}$ were probably too shórt to reach the equilibrium vacancy concentrations. Figures 1 and 2 indicate some degree of strengthening due to $\mathrm{Ni}$. However, if the equilibrium vacancy concentration at temperatures such as $673 \mathrm{~K}$ increases with an increase in the $\mathrm{Ni}$ concentration, as our experiments suggest, the observed strengthening might in principle be related to vacancies, and not to $\mathrm{Ni}$. More precise vacancy concentration measurements and microstructural observations will be needed to address this point.

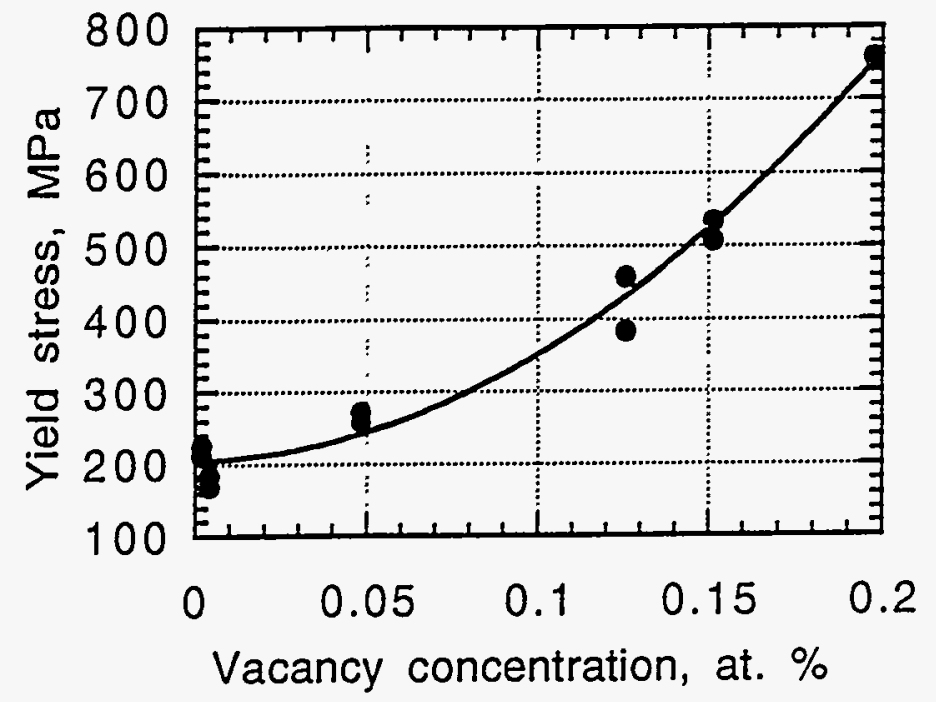

Fig. 6. Yield stress of Fe-45Al-0.1 Ni as a function of the vacancy concentration.

\section{ACKNOWLEDGMENTS}

This research was sponsored by the Division of Materials Sciences, U.S. Department of Energy under contract number DE-AC05-960R22464 with Lockheed Martin Energy Research Corporation.

\section{REFERENCES}

1. K. Ho and R. A. Dodd, Scr. Metall. 12, p. 1,055 (1978).

2. Y. Yang and I. Baker, submitted to Philos. Mag.

3. A.-S. Gay, A. Fraczkiewicz, and M. Biscondi. Journal de Physique IV. Colloque 2. supplément au Journal de Physique III 6, p. C2-153 (1996).

4. J. P. Rivière and J. Grilhé, Acta Metall. 20. p. 1275 (1972).

5. J. P. Rivière and J. Grilhé, Phys. Stat. Sol. (a) 25, p. 429 (1974).

6. J. P. Rivière and J. Grilhé, Scr. Metall. 9, p. 967 (1975).

7. P. Nagpal and I. Baker, Metall. Trans. A 21A, p. 2.281 (1990).

8. Y. A. Chang, L. M. Pike, C. T. Liu, A. R. Bilbrey, and D. S. Stone, Intermetallics 1, p. 107 (1993).

9. R. Würschum, C. Grupp, and H.-E. Schaefer, Phys. Rev. Letters 75, p. 97 (1995).

10. R. Würschum, K. Badura-Gergen. E. A. Kümmerle, C. Grupp, and H.-E. Schaefer, Phys Rev B 54, p. 849 (1996-ID)

11. C. L. Fu, Y.-Y. Ye, M. H. Yoo, and K. M. Ho, Phys. Rev. B 48, p. 6,712 (1993).

12. C. H. Kong and P. R. Munroe, Intermetallics 2, p. 333 (1994).

13. C. H. Kong and P. R. Munroe, Scr. Metall. Mater. 30, p. 1079 (1994).

14. P. R. Munroe, Intermetallics 4, p. 5 (1996).

15. P. R. Munroe and C. H. Kong, Intermetallics 4, p. 403 (1996).

16. P. R. Munroe, accepted for publication in Nickel and Iron Aluminides: Processing, Properties, and Applications, edited by S. C. Deevi et al., ASM. Cincinnati, OH, 1997.

17. J. H. Schneibel. E. P. George, E. D. Specht, and J. A. Horton in High Temperature Ordered Intermetallic Alloys - VI, edited by J. Horton et al. (Mater. Res. Soc. Proc. 364, Pittsburgh, PA. 1995), p. 73-8.

18. J. H. Schneibel, E. D. Specht, and W. A. Simpson, Intermetallics 4, p. 581 (1996). 